* Mestrando em Direito pela Universidade Estadual Paulista "Júlio de Mesquita Filho" (UNESP). Especialista em Gestão de Projetos com Formação para o Magistério Superior, na Área de Administração de Empresas pela Universidade Anhanguera (UNIDERP). E-mail: lfzen10@gmail.com.

* * Livre-docente da Universidade Estadual Paulista "Júlio de Mesquita Filho" (UNESP). Mestre e Doutor em Direito pela Pontifícia Universidade Católica de São Paulo (PUC -SP). E-mail: colomboarnoldi@yahoo.com.br.

\section{O ESTADO E A ATUAÇÃO EM PARCERIA COM A SOCIEDADE CIVIL NO DESENVOLVIMENTO DE AÇÕES DE INTERESSE PÚBLICO} THE STATE AND ITS PARTNERSHIP WITH CIVIL SOCIETY IN THE DEVELOPMENT OF ACTIONS OF PUBLIC INTEREST

\author{
Luiz Fernando Zen Nora* \\ Paulo Roberto Colombo Arnoldi**
}

Como citar: NORA, Luiz Fernando Zen; ARNOLDI, Paulo Roberto Colombo. O Estado e a atuação em parceria com a sociedade civil no desenvolvimento de ações de interesse público. Scientia Iuris, Londrina, v. 20, n. 2, p.51-80 jul. 2016. DOI: $10.5433 / 2178-8189.2016 v 20 \mathrm{n} 2 \mathrm{p} 51$. ISSN: $2178-8189$.

RESUMO: Face às crises frequentes sofridas pelos Estados Nacionais, este artigo realiza uma reflexão sobre o papel do Estado atual frente à uma nova dinâmica econômica e social de maior vontade de participação pela sociedade civil nas ações de interesse público. Visando cortar custos, cumprirá ao Estado reduzir o tamanho da máquina pública, que em muitos casos apresenta baixa eficiência. Para tanto, deverá repensar seu papel de 
"executor" para "fomentador" das ações, ao mesmo tempo em que precisará garantir o bom funcionamento das diversas formas de parcerias com o particular. Conclui-se, a partir da pesquisa bibliográfica realizada, que a relação público-privada deverá tomar uma nova feição, na qual o público utiliza instrumentos privados de gestão e o privado assume cada vez mais um papel responsável em relação à comunidade. Caberá ao Estado se abrir para novas formas de participação da sociedade e, por meio da governança, estabelecer novas formas de agir e coordenar as ações em parceria, desempenhando também um papel fiscalizador, de forma a garantir que seus contratos sejam bem cumpridos.

Palavras-chave: Governança pública; parcerias público-privada; Estado pósmoderno.

ABSTRACT: Given the frequent crises that countries suffer, this study provides a reflection on the current role of the State and analyzes the new economic and social dynamics that has had major participation of civil society - especially, in the actions relating to public interest. Nevertheless, the State also needs to reduce the size of its public machine, which is nowadays expensive and in most cases, inefficient. Therefore, the State must rethink its role as an "executor" to a 
"developer" when it comes to its actions and ensure the correct functioning of its various forms of partnerships, which it has with the private sector. Using the literature method, this study concludes that the public-private relationship needs to be seen from a new perspective, in which the public sector utilizes private management tools and the private sector partakes in a more responsible role within the community. However, the State, by using its governance, can establish new ways of acting and coordinating these measures in partnership with civil society; thus, it assumes a supervising position to ensure the completion of these contracts.

Keywords: Public governance; public-private partnerships; post-modern State. 


\section{INTRODUÇÃO}

Face às crises frequentes sofridas pelos Estados Nacionais, este artigo realiza uma reflexão sobre o atual papel do Estado frente à uma nova dinâmica econômica e social, trazida especialmente em função da globalização, fim do Estado de Bem-Estar social e também pelo neoliberalismo imperante na economia. De forma mais abrangente e sucinta, verifica-se nas palavras de Diogo de Figueiredo Moreira Neto (2014, p. 605):

São, com efeito, problemas emergentes - como os suscitados pela exploração das comunicações, pela globalização, pela competição interna e externa por mercados, por recursos e por cérebros, pela crescente resistência social ao aumento de tributos e pelo despertar das massas para a participação política - que não encontram respostas nos aparelhos políticos de Estado herdado do século findo, com seus remanescentes novecentistas.

Diante de novos e velhos desafios, especialmente a redução de recursos e o excesso de burocracia, para a manutenção da governabilidade cumpre aos administradores públicos repensarem suas formas de gestão, especialmente aumentando seu relacionamento com a sociedade civil de modo a aproveitar as potencialidades surgidas desta relação.

Este artigo procura verificar a possibilidade e necessidade de uma mudança da visão dicotômica que separa a sociedade civil do Estado e, especialmente, o público do privado visando proporcionar maior eficiência à ação estatal com o compartilhamento de suas ações com o setor privado. Com isso desenvolve-se a compreensão de que o “interesse público" também pode ser um objetivo de ações realizadas 
por entidades privadas, lucrativas ou não, muitas vezes em parceria com a administração pública.

O Estado está diante de uma dinâmica social na qual a lógica do mercado tem um papel considerável e o mais importante é atuar ao lado um do outro, em parcerias. Isso significa dizer que é imperativo a construção de uma interação real entre a gestão pública, o setor privado e a sociedade civil organizada. $\mathrm{O}$ new public management surge como resposta para várias questões como a reforma, a modernização, a lógica dos resultados, assim como a participação de diferentes atores sociais no processo de elaboração das políticas públicas (SILVA, 2008, p. 86).

Para esta aproximação entre o público e o privado na realização de ações para o interesse comum, ganha destaque a discussão sobre a necessidade do estabelecimento de novas formas de parcerias que possam garantir a efetividade dos processos. Faz-se necessário que exista uma nova forma de relacionamento mais horizontal e melhor contratada, no sentido das especificações das ações e responsabilidades de cada entidade, bem como maior fiscalização os contratos, partindo-se para uma lógica de focar nos resultados e não deixar que os processos, ou seja a burocracia, atrapalhe a persecução das metas principais de cada ação no sentido de realmente atender o interesse público.

\section{A DICOTOMIA ESTADO E SOCIEDADE CIVIL}

Atualmente o Estado deve se adaptar para enfrentar as crises 
de governabilidade, especialmente das advindas crises econômicas cada vez mais frequentes, haja vista o momento de depressão que teve início em 2008, entre outras.

Em tempos de crise fica evidente a dicotomia entre sociedade civil e Estado, uma vez que aumentam as necessidades e as demandas sociais, porém as instituições estatais já não conseguem dar uma resposta satisfatória em função da consequente queda da arrecadação de tributos que limita sua capacidade de investimento no social. De acordo com Norberto Bobbio (2014, p. 36) "o contraste entre sociedade civil e Estado põe-se então como contraste entre quantidade e qualidade das demandas e capacidade das instituições de dar respostas adequadas e tempestivas".

Dentro deste viés dicotômico, pode ser observada ainda uma relação axiológica na qual, dependendo da situação, verifica-se que um polo se sobrepõe ao outro, como exemplo, ao valorizar a propriedade privada sobre o interesse do próprio Estado - o que hoje pode se traduzir no Brasil no excesso de proteção ao patrimônio privado impondo dificuldades para a desapropriação de terras pelo Estado para a reforma agrária ou mesmo para a construção de uma creche -, ou ao supervalorizar o público em relação à autonomia privada - especialmente em relação ao controle das questões econômicas pelo Estado no modelo de Estado de Bem-Estar Social ${ }^{1}$.

Desta maneira dicotômica, pode-se observar o contraste entre os tipos de Estado da modernidade: o Estado Liberal, cujo primado do privado requer o Estado mínimo, deixando as questões econômicas à mercê das regras de mercado, e o Estado de Bem-Estar Social, baseado

1 Observa-se que o Estado de Bem-Estar Social, conforme Maria Sylvia Zanella Di Pietro (2014, p. 9), também foi chamado de Estado Social, Estado Providência, Estado do desenvolvimento e Estado Social de Direito, "nele o Estado deve intervir na ordem econômica e social para ajudar os menos favorecidos; a preocupação maior desloca-se da liberdade para a igualdade." 
no intervencionismo estatal para a promoção do desenvolvimento econômico e social do país.

Assim, na história mais recente houve uma alternância de modelos de Estado em função das necessidades econômicas e preponderâncias políticas de cada momento. No Estado Liberal houve a ascensão da burguesia e a necessidade de um Estado que permitisse o avanço de sua ideologia, ou seja, uma maior liberdade ao indivíduo para poder negociar e também a proteção à propriedade privada. Porém, o excesso de liberdade em relação à propriedade privada provocou um grau muito alto de disparidades sócio econômicas, o que terminou por gerar uma grande crise.

A partir da crise do Estado Liberal surge, principalmente com a teoria de Keynes, o Estado de Bem-Estar Social, que deveria assumir o controle da economia e garantir direitos básicos aos cidadãos, tais como emprego, assistência médica, moradia e outros. Porém tais cuidados geraram uma máquina administrativa pesada e um alto preço a pagar, que se traduziu em uma alta carga tributária e o excesso de intervenções na economia, ou seja, um custo que se voltou contra os próprios cidadãos.

O Estado, ao mesmo tempo em que foi chamado a agir nos campos social e econômico, para assegurar a justiça social, passou a pôr em perigo a liberdade individual, pela crescente intervenção que vai desde a simples limitação ao exercício de direitos até a atuação direta no setor da atividade privada, com a agravante de não alcançar a realização dos direitos sociais e individuais nos vários setores da sociedade (DI PIETRO, 2015, p. 14).

Ocorre que com o avanço das tecnologias de transporte e 
telecomunicações, que facilitaram o comércio entre países, cresceram as empresas multinacionais e transnacionais que passaram a dividir seus processos produtivos em países diferentes, aproveitando-se das "facilidades" oferecidas em cada local, buscando a redução do custo de produção e a obtenção de maiores vantagens no momento da comercialização, ou seja, a realização de mais lucro. Esse movimento da indústria em busca de locais mais vantajosos gerou uma certa volatilidade nos investimentos empresariais, que se deslocam na medida em que recebem maiores benefícios de outro local, impactando fortemente a economia dos países ou regiões dos quais o investimento é retirado.

Com o fortalecimento do poder de grandes grupos econômicos, mais uma vez as ideologias liberais voltam à tona e ressurge o Estado liberal, agora chamado de Estado Neoliberal. Nesta nova fase ressurgem os estímulos para que os países se abram aos capitais externos viabilizandose um grande fluxo financeiro mundial, de tal forma que a queda na bolsa em um país da Ásia afeta a economia dos outros países do mundo. Surge um mercado especulativo que cria bolhas de supervalorização das ações, que do dia para a noite caem e levam ao chão seus investidores e junto a economia de países inteiros!

Ademais, influenciando as ações estatais, surgem as comunidades de países, como a União Europeia - UE, cujos acordos passam a limitar a atuação dos governos e até mesmo sugerir medidas econômicas impopulares para a integração dos países com menores condições financeiras no bloco.

Como ciclos, novamente as crises econômicas retornam gerando a ingovernabilidade dos Estados que ainda são geridos de forma tradicional e burocrática. Daí a necessidade de mudanças, pois o Administrador Público perde sua legitimidade quando não age para 
enfrentar as dificuldades e não assume suas responsabilidades em relação ao atendimento das necessidades básicas de seus "administrados" ou seja, seu povo. Ao não agir, a sociedade civil tende a retomar seu poder, buscando novas saídas, que tendem a gerar processos de mudança, que podem chegar ao nível institucional da organização estatal.

Estreitamente ligado ao tema da ingovernabilidade está o da legitimação: a ingovernabilidade gera crise de legitimidade. Também este tema pode ser traduzido nos termos da mesma dicotomia: as instituições representam o poder legítimo no sentido weberiano da palavra, isto é, o poder cujas decisões são aceitas e cumpridas na medida em que consideradas como emanadas de uma autoridade à qual se reconhece o direito de tomar decisões válidas para toda a coletividade; a sociedade civil representa o lugar onde se formam, especialmente nos períodos de crise institucional, os poderes de fato que tendem a obter uma legitimação própria, inclusive em detrimento dos poderes legítimos - o lugar onde, em outras palavras, desenvolve-se os processos de deslegitimação e de relegitimação (BOBBIO, 2014, p. 36).

Se o Estado já não consegue ter a eficiência necessária e perde sua legitimidade, tende-se a fortalecer a sociedade civil que vem cada vez mais se organizando na forma de grupos privados empresariais e também de associações não lucrativas, chamadas de entidades do terceiro setor, para não só exigir da gestão pública, mas também agir por si só, assumindo um papel responsável pelo desenvolvimento não só na economia, mas também em outras áreas, como saúde, educação, assistência social e meio ambiente. Assim, a própria comunidade vem buscando colaborar como parceira do Estado nos processos de reorganização estatal para garantir 
o atendimento de suas necessidades.

Para o envolvimento da sociedade civil nas ações estatais, as administrações públicas devem se reestruturar e se adaptar à uma nova forma de gestão e compartilhamento de ações. Bobbio observa que o Estado contemporâneo vive uma inter-relação entre ambos e, para conseguir atingir seus fins, necessita agir através de acordos e não da imposição de suas decisões.

Os dois processos, de publicização do privado e de privatização do público, não são de fato incompatíveis, e realmente compenetram-se um no outro. O primeiro reflete o processo de subordinação dos interesses do privado aos interesses da coletividade representada pelo Estado que invade e engloba progressivamente a sociedade civil; o segundo representa a revanche dos interesses privados através da formação dos grandes grupos que se servem dos aparatos públicos para o alcance dos próprios objetivos. O Estado pode ser corretamente representado como o lugar onde se desenvolvem e se compõem, para novamente decompor-se e recompor-se, estes conflitos, através do instrumento jurídico de um acordo continuamente renovado, representação moderna da tradicional figura do contrato social (BOBBIO, 2014, p. 27).

Nesse sentido, Moreira Neto (2014, p. 46) oferece um conceito para o Direito Administrativo, que se propõe a superar as visões políticas de administração pública incorporadas pelo Estado Liberal e pelo Estado de Bem-Estar Social, a primeira com uma tendência mais libertária e a segunda com um tendência mais igualitária, bem como procura expandir a compreensão monopolista do administrador público para uma visão pós-moderna, que promove o direito do administrado e o Estado como 
parceiro da sociedade em busca do desenvolvimento que garanta os direitos fundamentais a todos, desta forma:

Direito Administrativo é o ramo do Direito Público que estuda os princípios, regras e institutos que regem as atividades jurídicas do Estado e de seus delegados, as relações de subordinação e de coordenação delas derivadas e os instrumentos garantidores da limitação e do controle de sua legalidade, legitimidade e moralidade, ao atuarem concreta, direta e imediatamente, na prossecução dos interesses públicos, excluídas as atividades de criação da norma legal e de sua aplicação judiciária contenciosa (MOREIRA NETO, 2014, p. 46)

Evidencia-se que os princípios da legalidade, legitimidade e moralidade condicionam, mas não limitam a "prossecução dos interesses públicos" na atuação finalística da administração pública. Desta maneira, segundo este autor, o direito administrativo passa a ressignificar o Estado "enquanto instrumento e parceiro da sociedade na funcionalização de seus direitos fundamentais" (MOREIRA NETO, 2014, p. 46).

\section{O ESTADO DEMOCRÁTICO}

Ao ressignificar a compreensão do Estado pelo seu agir, deve-se também remodelá-lo em relação à sua estrutura jurídica para a institucionalização do novo modelo mais participativo. Para Di Pietro (2015, p. 14), diante das consequência negativas surgidas com o Estado de Bem-Estar Social - intervencionista e ineficaz para a solução dos problemas atuais - e do positivismo jurídico gerado pelo apego ao estrito 
cumprimento da lei escrita, foi acrescentado à ideia de "Estado de Direito" o conceito de democracia, almejando-se uma maior participação popular no processo político, decisões do Governo e controle da Administração Pública, o que levou ao surgimento da expressão "Estado de Direito Social e Democrático". Nessa nova concepção ocorre a humanização da ideia de "interesse público", que passa a integrar os "valores considerados essenciais à existência de uma vida digna". Já não basta a liberdade, se não houver dignidade.

Continua cabendo ao Estado diminuir as desigualdades sociais e buscar o bem-estar social para todos, porém, nesta nova visão democrática, o princípio da legalidade não pode ser identificado dentro de uma visão formalista, "vazia de conteúdo e eficácia", mas passa a fazer referência ao ordenamento jurídico como um todo, contemplando inclusive os princípios, "independentemente de sua previsão expressa no direito positivo".

Portanto, o interesse público deixa de ser entendido como o interesse do Estado, para efetivamente ser concebido como o interesse da sociedade, cuja defesa é justamente uma das funções precípuas do Estado, inclusive fazendo sua mediação dentre os diversos grupos sociais que o compõem. Eli Diniz (1996, p. 15) entende que o conceito de interesse público "deve refletir a operação eficiente das instâncias de agregação, onde se dá a compatibilização do leque diversificado e contraditório das demandas sociais."

Nesse sentido, para Gustavo Justino de Oliveira (2006, p. 89), seria função do Estado a "harmonização da perspectiva do crescimento econômico com o desenvolvimento humano e comunitário". Nessa linha, Moreira Neto defende que a legalidade restrita perde espaço para o surgimento da materialidade da democracia, que carrega consigo os 
valores da legitimidade e moralidade. O Direito Administrativo está cada vez mais se constitucionalizando, como outros ramos do direito interno, o que tem produzido mudanças significativas, sendo chamado de neoconstitucionalismo, e elenca os seguintes aspectos:

1 - a supremacia dos direitos fundamentais constitucionais; 2 - a força preceptiva das normas constitucionais, sejam elas regras ou princípios; 3 - a sobreinterpretação da Constituição, para dela deduzir princípios implícitos; 4 - a universalidade aplicativa da Constituição, ou seja, a possibilidade de aplicação direta sobre todas as relações jurídicas, seja de que ramo forem; e 5 - a orientação ética da Constituição, com rigoroso respeito aos valores implícitos nos direitos fundamentais e no seu ethos democraticamente legitimado (MOREIRA NETO, 2014, p. 73, grifos do autor).

Não basta a administração seguir estritamente a lei, se não promove os direitos fundamentais e não consegue executar suas ações com a aprovação da sociedade civil, ou seja, dos administrados. Ou, pior, se seguindo a lei age de forma imoral em suas escolhas, através da discricionariedade, como por exemplo, priorizando a construção de um museu ao invés de um hospital em uma comunidade que não possui atendimento médico suficiente.

Para evitar decisões que o farão perder a legitimidade, o caminho seria abrir-se cada vez mais para a participação popular mais direta criando e aperfeiçoando instrumentos de gestão que permitam que isto aconteça de forma ordenada. A sociedade civil deseja cada vez mais a democracia não apenas representativa, mas também participativa e neste sentido, além de escolher seus representantes, quer contribuir na 
definição das políticas públicas a serem implantas e também participar de sua execução, em colaboração com a administração pública (MOREIRA NETO, 2014, p. 605).

Com isso é quebrada a dicotomia irredutível que separa o Estado da Sociedade civil que, segundo Sabino Cassese (2010, p. 84), ocorre no modelo tradicional polarizado, não apenas em função dos conflitos, mas também por serem regidos por regras diversas. A ideia comum surgida com o Estado de Direito e o avanço do direito administrativo, especialmente a partir de que o público somente pode agir de acordo com a lei, enquanto o privado pode agir somente limitado pelo que a lei proíbe, acabou por reforçar esta dicotomia e inclusive contribuiu para o desequilíbrio entre os Poderes Legislativo e Executivo, uma vez que a lei passou a ser mais valorizada que a ação de governar.

A diferenciação entre o modelo de agir público, vinculado ao fim, e do agir privado, livre em seu fim e limitado pelo direito apenas externamente, também se formou de maneira lenta com a crise do estado patrimonial e com a afirmação da supremacia do Parlamento sobre a administração e, portanto, da lei sobre a atividade executiva (CASSESE, 2010, p. 85).

Com o fim desta visão dicotômica, o Estado deve abrir-se para um aumento do intercâmbio com a sociedade, no qual o Poder Público não apenas permite uma maior participação dos administrados, como também passa a utilizar, na medida do possível, as formas de gestão das empresas privadas, buscando praticidade, economicidade, eficácia e eficiência, através do foco nos resultados, que no caso das empresas é fundamental para sua sobrevivência. 


\section{A PARCERIZAÇÃO}

Ademais, um sistema participativo promove mudanças também na forma de contratação pelo Estado, deixando um pouco sua posição até então entendida como superior, para dialogar de forma horizontal com as empresas e entidades do terceiro setor, contratando através de acordos e não imposições e convidando a sociedade à contribuir no desenvolvimento de suas ações.

Dessarte, espera-se que o Estado contemporâneo aguce sua capacidade policêntrica da atualidade, não somente estabelecendo canais de participação e interlocução com seus representantes (participação administrativa), mas igualmente criando vínculos, acordos, alianças e parcerias com entidades empresariais e sociais (concertação administrativa) (OLIVEIRA, 2006, p. 89, grifos no original)

Desta forma, para que a Administração Pública possa exercer seu papel de cuidado e desenvolvimento, cumpre a reflexão sobre os modos de contratar do Estado, de como realiza suas parcerias para conseguir agir com eficácia e eficiência. Nesse sentido, faz-se necessária uma relação de maior autonomia entre os contratantes, sendo que o modo "impositor" estatal deve dar lugar à uma maior capacidade de negociação, que trará aos seus contratos maior legitimidade, uma vez que a negociação abre a possibilidade do diálogo - quase inexistente nos processos licitatórios atuais - e com isso maior possibilidade de existirem maiores expectativas atendidas para todas as partes, sejam órgãos estatais, sejam entidades da sociedade civil, que visam lucro ou não no objeto do contrato, e até a 
própria comunidade, quando é chamada a opinar em audiências públicas por exemplo.

Uma vez que o Administrador Público percebe que o "interesse público" não é exclusivo do Estado, apesar de ser sua prerrogativa principal, sendo que a sociedade civil também pode e tem interesse em atuar nesta área, cabe abrir-se para as possibilidade de desenvolvimento de ações em colaboração, mas para isso deverá se preparar, pois os processos de negociação são fundamentais para o sucesso da execução contratual.

Assim surge um "novo contratualismo administrativo" que, conforme Oliveira (2006, p.102), é diferente da atual forma de contratar pelo Estado, introduzindo uma maior paridade entre a Administração Pública e o particular, favorecendo a negociação entre ambos, bem como melhor estabelecendo a interdependência entre as prestações de ambas as partes. Desta forma ele elenca que:

(i) Privilegia-se sobremaneira a cultura do diálogo entre o parceiro público e o privado, (ii) confere-se maior atenção às negociações preliminares ao ajuste (que devem ser transparentes), (iii) abrem-se espaços para trocas e concessões mútuas entre os parceiros, visando um balanceamento dos interesses envolvidos, (iv) diminui-se a imposição unilateral de cláusulas por parte da Administração, com o proporcional aumento da interação entre os parceiros para o delineamento e fixação das cláusulas que integrarão o contrato e (v) institui-se uma maior interdependência entre as prestações correspondentes ao parceiro público e ao parceiro privado, inclusive com a repartição dos riscos e atribuição de garantias a esse último, tidas como não usuais nos contratos tradicionais firmados pela Administração (OLIVEIRA, 2006, p. 107). 
Em um estudo de caso, analisando a legislação que instituiu a "Conferência de Serviços" na Itália - um sistema criado para a aprovação dos projetos executivos das obras relativas às redes ferroviárias e que seria composta pelas administrações estatais e por entes públicos territoriais e não territoriais, bem como por outros sujeitos públicos com competência nesta área -, Cassese $(2010$, p. 96) revela que esta norma teve duas características principais: buscou tornar "colegial como norma o agir administrativo", compensando o policentrismo organizacional em função dos diversos órgãos públicos e territórios envolvidos - com a unicidade da decisão; e criou um espaço no qual tornou mais rápido o agir administrativo, através da justaposição de decisões, que de outro modo seriam tomadas de forma sequencial. Ademais, tornou-se um local no qual as negociações permitem que concessões recíprocas sejam definidas para resolução das questões. Observa-se ainda que a despeito da norma prever apenas contratos entre a administração pública, este autor ressalta que na prática não ocorre bem assim, pois junto às regras que disciplinam as Conferências de Serviços, também foram utilizadas leis que promoveram entre as partes interessadas um "acordo de programa"2 e possibilitaram a abertura para a participação dos sujeitos privados nas negociações.

Para os acordos vale também o que ocorre para as Conferências de Serviços. Eles são, com frequência, considerados, com interpretação mecanicista, instrumento de simplificação, aceleração ou garantia

2 Segundo Moreira Neto (2014, p. 212), acordo de programa é um instituto de aplicação recente no Brasil, embora já muito utilizado na Europa, trata-se de um instrumento adequado para o desenvolvimento de um sistema de administração multipolarizado e aberto, que favorece a administração por objetivos e com estímulos à parcerias consensuais, podendo ser públicas e privadas, desde que ao menos uma das partes seja uma entidade administrativa pública. 
de coordenação, mas são, na realidade, contratos de negociação. Um acordo não se realizaria apenas por justaposição das manifestações, concomitantes, de vontades dos diferentes sujeitos públicos. Para alcançá-lo é essencial que exista negociação, com uma parte cedendo em um ponto, outra em outro, de modo que se atinja um equilíbrio entre interesses contrapostos, que permaneceriam imutáveis sem a negociação. O conteúdo desta constitui, portanto, o aspecto essencial do acordo (CASSESE, 2010, p. 98).

Desta forma, na análise de caso enfrentada por Cassese (2010, p. 103), o autor verificou que a participação dos sujeitos privados trouxe força para o processo da negociação, sendo que as garantias pactuadas pelas empresas em relação aos governos locais trouxe maior segurança para os municípios participantes. Esta abertura das administrações públicas para as negociações, atuando através de acordos, mesmo quando detém o poder autoritário, demonstra um novo papel do Estado, no qual ele "prevê e consente, não obriga ou comanda" e ainda age muitas vezes como sujeitos privados e "pedem segurança por meio de garantias".

\section{O ESTADO FOMENTADOR}

Somado a esta nova forma de gestão, mais aberta à negociação nas suas contratações em busca de uma maior eficiência e redução da máquina pública, também cabe ao Estado fomentar a participação da sociedade civil no desenvolvimento de ações de interesse público e que busquem as garantias de direitos fundamentais. Neste sentido, desde que exista uma lei que o permita, ele passa a oferecer incentivos públicos 
diversos - recursos financeiros, técnicos, equipamentos, serviços, entre outros - para os entes privados.

Segundo Juan Alfonso Santamaria Pastor, a atividade de fomento estatal surge a partir do momento em que o Estado deixa de agir como uma estrutura de dominação e passa a assumir seu papel no desenvolvimento social e econômico da nação.

Desde los tiempos em que el Estado comienza a considerar como un objetivo primordial el bienestar de los súbditos y el incremento de su riqueza, se pone de manifiesto que diversas actividades que llevan a cabo los sujetos privados presentan um grado de coincidência natural com los objetivos de interés general que persigue institucionalmente la Administración: son actividades cuya realización es descable desde el punto de vista del Estado, pero que éste, por razones muy diversas, no puede empreender por sí solo. Por ello, frente a dichas actividades no cabe outra actitud posible que estimular a dichos sujetos a desarrollarlas y, em su caso, orientarlas de manera que se optmice el beneficio coletivo que generan y se eviten eventuales desviaciones em su ejecución (SANTAMARIA PASTOR, 2009, p. 350).

São várias as formas de fomento público, que podem ser classificados, de acordo com seus fins (MOREIRA NETO, 2014, p. 577- 612), como:

a) Planejamento Estatal, que cuida das formas de intervenção do próprio Estado na economia de modo a produzir o desenvolvimento econômico. No caso do Brasil, está previsto no artigo 174 da Constituição Federal, que em seu parágrafo primeiro diz: “A lei estabelecerá as 
diretrizes e bases do planejamento do desenvolvimento nacional equilibrado, o qual incorporará e compatibilizará os planos nacionais e regionais de desenvolvimento". Desta forma o Estado deve criar políticas de desenvolvimento regional buscando um equilíbrio entre as regiões e estados brasileiros, no que entram políticas específicas como isenções, reduções temporárias de tributos, juros favorecidos em empréstimos, e inclusive a criação de bancos regionais para financiamentos, entre outras medidas. Hoje, cada vez caindo mais em desuso, uma opção que também já foi adotada pelo Estado foi a atividade econômica suplementar à atividade privada, na qual surgiram as empresas estatais.

b) Fomento público Social ao desenvolvimento humano, no qual o objetivo do fomento público é o desenvolvimento das pessoas, buscando uma vida digna para cada um, como exemplo, a gratuidade do casamento civil e muitos outros previstos no artigo 226 e seguintes da CF que buscam garantir a efetividade do atendimento das necessidades básicas para todos e todas.

c) Fomento público social da educação, pesquisa e informação, por exemplo, vedando a instituição de impostos para entidades de educação sem fins lucrativos, oferecendo imunidade tributária aos livros, jornais e revistas e com a instituição de órgãos como o Conselho Nacional de Pesquisas - CNPq.

d) Fomento público social do trabalho, voltado ao estabelecimento de melhores condições e instrumentos legais aos trabalhadores, nessa linha, entre 
diversas outros instrumentos, destaca-se a legislação que instituiu os entes de colaboração do chamado "Sistema S", órgãos de apoio ao trabalhador, cujo nomes são auto explicativos: o Serviço Nacional de Aprendizagem Industrial - SENAI e o Serviço Social da Indústria - SESI, no setor industrial, o Serviço Nacional de Aprendizagem Comercial - SENAC e o Serviço Social do Comércio - SESC, no setor comercial; e por fim o Serviço Nacional de Aprendizagem Rural - SENAR, no setor rural.

e) Fomento público social da Cultura, do Lazer, dos Desportos e do Turismo, que trata dos fomentos voltados ao desenvolvimento da cultura, do lazer, dos desportos e do turismo. Para o fomento cultural, foi prevista a proteção do patrimônio histórico-cultural brasileiro, a implantação de institutos de artes, estímulo à produção artística e diversos outros pontos com previsão constitucional principalmente nos artigos 215 e 216; para o fomento do turismo, inclusive fator de desenvolvimento econômico previsto no artigo 180 da CF, entre outras ações, visando estimular iniciativas públicas e privadas, foi criada a Empresa Brasileira de Turismo - EMBRATUR, que dentre as diversas funções destacam-se para o tema deste artigo: promoção e divulgação do turismo nacional; fomentar ou financiar iniciativas que visem o desenvolvimento da indústria do turismo; definir critérios, bem como acompanhar os projetos de empreendimentos turísticos que sejam financiados ou incentivados pelo Estado.

f)

Fomento Público Social Ambiental, que 
visa a efetiva proteção e melhoria do meio-ambiente, estabelecendo possibilidades positivas de atuação estatal nesta área, frente às ações coercitivas. Serve para todas as ações elencadas no artigo 225 da $\mathrm{CF}$, como exemplo: preservar e restaurar os processos ecológicos essenciais das espécies e ecossistemas e "promover a educação ambiental em todos os níveis de ensino e a conscientização pública para a preservação do meio ambiente". Este tipo de fomento, ultimamente, vem sendo utilizado também para o estímulo às empresas a evitarem ou reduzirem seus danos ambientais.

g) Fomento público social rural, que estimula a produção, bem como também busca que a função social da propriedade agrária seja cumprida, de modo a promover a reforma agrária em terras improdutivas e também fornecer condições para a sua utilização, como incentivos creditícios e fiscais, assistência técnica, seguro agrícola e outros itens previstos no artigo $187 \mathrm{da} \mathrm{CF}$.

h) Fomento público econômico à empresa, diante da importância econômica e social que os empreendimentos econômicos dos particulares oferecem ao Estado, especialmente em função da geração de emprego e renda, e ainda contribuindo inclusive para o equilíbrio da balança econômica das comercializações entre países, o fomento trata-se de algo fundamental. Buscando um maior impacto social, são especialmente incentivadas as cooperativas (em função do artigo $170, \S 2^{\circ}$ da CF) e as microempresas e empresas de pequeno porte, que contam 
com apoio constitucional no artigo 170, inciso IX e ainda no artigo 179, além das leis complementares 123/2006 e $147 / 2014$, entre outras.

i) Fomento público de atividades econômicas primárias, trata do estímulo aos setores primários da produção, setor estratégico base para a geração de matéria prima e alimentos para o país. Aqui, entre outros, verificase o fomento ao setor agropecuário, à pesca e à produção mineral.

j) Fomento público científico e tecnológico, disposto no artigo 218 da $\mathrm{CF}$, “o Estado promoverá e incentivará o desenvolvimento científico, a pesquisa, a capacitação científica e tecnológica e a inovação". Sem dúvida, o desenvolvimento tecnológico é um importante estímulo ao desenvolvimento nacional.

k) Fomento público financeiro e creditício, aqui o incentivo será através de recursos financeiros que não somente poderão vir do Estado, mas também a partir de investimentos de capital estrangeiro, vide artigo 172 da CF. Há que ser comentado que além dos bancos públicos, os bancos, as sociedades creditícias, de financiamento e de investimentos particulares também coadunam com o sistema de fomento financeiro oficial. Também há que se considerar os incentivos fiscais, através dos quais a União, os Estados, o Distrito Federal e os Municípios exercem a função metafiscal do tributo, fazendo com que ele sirva não apenas para fins arrecadatórios, mas gerando estímulos a determinadas atividades econômicas ou sociais. 
Por fim, verifica-se o Fomento Institucional ao setor público não estatal, surgido justamente através da pluralização dos canais de participação da sociedade civil nas ações de interesse público, visando estimular entidades que atuam em colaboração com o Estado e até mesmo onde o Estado não consegue chegar, inclusive desenvolvendo ações em todas as frentes de fomento comentadas acima.

Especialmente através desta linha de fomento, o Estado procura reduzir suas iniciativas diretamente nas comunidades e repassá-las para entidades da sociedade civil, muitas vezes inseridas nas próprias comunidades que serão atendidas pelas políticas públicas em questão. Desta forma o Estado diminui seu tamanho, cujo peso é atualmente insustentável, e também consegue uma melhor atuação, pois a proximidade e o entendimento local da entidade parceira muitas vezes vai facilitar a boa execução do contrato e obter melhores resultados para todas as partes envolvidas, especialmente os beneficiários.

A parceria serve ao objetivo de diminuição do tamanho do aparelhamento do Estado, na medida em que delega ao setor privado algumas atividades que hoje são desempenhadas pela Administração, com a consequente diminuição ou extinção de órgãos públicos e entidades da administração indireta, e diminuição no quadro de servidores; serve também ao objetivo de fomento à iniciativa privada, quando seja deficiente, de modo a ajuda-la no desempenho de atividades de interesse público; e serve ao objetivo de eficiência, porque introduz, ao lado da forma tradicional de atuação da Administração Pública burocrática, outros procedimentos que, pelo menos teoricamente (segundo os idealizadores da Reforma), seriam mais adequados a esse fim de eficiência (DI 
PIETRO, 2015, p. 25, grifos da autora).

Segundo Moreira Neto (2014, p. 608), este tipo de fomento promove duas grandes vantagens: a política e a técnica. A vantagem política se dá em função da própria abertura da participação dos administrados, aumentando o clima de colaboração e a legitimidade das decisões tomadas pela administração pública. Já a vantagem técnica está na despolitização das decisões, que não seriam tomadas apenas por pessoas ocupando cargos políticos e muitas vezes descomprometidas "pessoalmente" com os resultados, uma vez que não seriam beneficiados diretamente por eles, mas passam a ser tomadas, e muitas vezes executadas, pelos próprios grupos sociais interessados e que são justamente os que mais precisam que aquela ação dê certo. Ademais, ainda existe uma vantagem fiscal para o Estado, na medida em que estas entidades passam a executar ações de interesse público e propiciam a redução dos custos e da necessidade de contratação de mais funcionários públicos, especialmente diante do fato de que a maioria das administrações já se encontram próximas do limite legal de gastos com suas folhas de pagamento de recursos humanos.

\section{A GOVERNANÇA}

Para que todo este novo arranjo funcione, faz-se necessária uma forma de atuação que coordene todas as partes envolvidas, ou seja, os órgãos públicos, as entidades parceiras executoras, as entidades envolvidas nos processos decisórios e também os próprios beneficiários. Oliveira (2008, p. 26), chama atenção para um termo que vem contribuindo para o entendimento desta nova postura estatal, a governança, "cujo significado 
para o poder público liga-se primordialmente ao campo da efetividade da ação governamental", ou seja, a amarração das partes garantindo os processos e resultados.

Quanto ao uso deste termo, Diniz (1996), explica que a governabilidade seria a forma do exercício do poder, como as "características do sistema político, a forma de Governo (parlamentarismo ou presidencialismo), as relações entre os poderes (maior ou menor assimetria, por exemplo), os sistemas partidários", entre outros. Já a "governance" é entendida para Diniz (1996, p. 12-13), como o "conjunto dos mecanismos e procedimentos para lidar com a dimensão participativa e plural da sociedade, o que implica expandir e aperfeiçoar os meios de interlocução e de administração do jogo de interesses." A autora completa reforçando que a governança vem da necessidade do Estado ter maior flexibilidade, descentralizar funções e transferir responsabilidades, mas "sem abrir mão dos instrumentos de controle e supervisão."

Dessa forma surge o Estado Pós-moderno, que incorpora novos conceitos participativos e busca uma maior integração com a sociedade que o constitui, especialmente em busca da efetividade das ações que deve refletir em legitimidade para a administração pública, justamente pela sua capacidade de envolver a sociedade nas suas decisões e ações através da governança.

Rompendo com a dogmática jurídica inerente à modernidade, o direito pós-moderno - direito plural, direito negociado, direito flexível, direito reflexivo apresenta ainda novas características relativamente ao direito moderno: incorporando a complexidade do real, ele se transforma em instrumento flexível de pilotagem e de governança; meio de "governo" das sociedades, ele se torna instrumento de uma 
"governança" que segue as vias mais sinuosas (CHEVALLIER, 2009, p. 182).

O Estado deve ser capaz de se ajustar aos diferentes interesses da sociedade, buscando sempre o bem comum, assim deverá ir além das já usuais ações de comando e implementação para também assumir papéis de coordenação e administração de conflitos (DINIZ, 1996, p. 14), com foco na eficiência das ações, a despeito de uma visão anterior de garantia dos meios em detrimento dos próprios fins.

\section{CONCLUSÃO}

Verificou-se que o Estado precisa repensar sua maneira de agir para conseguir assumir suas responsabilidades frente ao desenvolvimento social e econômico. As dificuldades geradas com o agravamento das crises econômicas e os efeitos da globalização aumentaram a necessidade da participação do cidadão nas decisões e ações estatais, caso contrário o Estado pode perder sua legitimidade e sua capacidade de solucionar os problemas sociais da atualidade.

Para o ente estatal ganhar eficiência deverá desfazer as dicotomias que o separam da sociedade civil e precisará realizar parcerias com sujeitos privados diversos, sejam empresas ou entidades de terceiro setor, bem como compor os interesses dos diversos entes das administrações públicas locais, estaduais e municipais, autarquias, e sociedades de economia mistas no âmbito interno, como também deverá respeitar acordos internacionais e trabalhar em conjunto com outros países para minimizar os impactos das crises, hoje mundiais, e 
participar de soluções globais.

Como a superioridade política do Estado perdeu espaço mediante o avanço da superioridade econômica de grandes empresas e grupos empresarias, evidenciou-se que as melhores soluções não serão encontradas a partir de decisões hierarquizadas, mas sim através de acordos mediante negociações em pé de igualdade entre todas as partes independente de suas origens, sejam pertencentes ao Estado ou à sociedade civil.

A relação público-privada deverá tomar uma nova feição, na qual o público utiliza instrumentos privados de gestão e o privado assume cada vez mais um papel responsável em relação à comunidade, ao interesse comum. Assim, a dicotomia entre público e privado, como se somente tivessem interesses opostos ou antagônicos, deverá ser deixada de lado em busca da eficiência e eficácia das ações fins do Estado e do bem comum.

Desta feita, cumprirá ao Estado reduzir o tamanho da máquina pública, hoje custosa e com baixa eficiência. Para tanto, deverá repensar seu papel de "executor" para "fomentador" das ações, ao mesmo tempo em que precisará garantir o bom funcionamento das diversas formas de parcerias, por meio da governança, desempenhando também um papel fiscalizador, de forma a garantir que seus contratos sejam cumpridos, ou em caso de dificuldades na sua execução, que os problemas sejam descobertos com antecedência para que seja possível a revisão contratual e correção dos rumos.

\section{REFERÊNCIAS}


BOBBIO, Norberto. Estado, governo, sociedade: por uma teoria geral da política. 19. ed. Rio de Janeiro: Paz e Terra, 2014.

CASSESE, Sabino. A crise do Estado. Campinas-SP: Saberes Editora, 2010.

CHEVALLIER, Jacques. O Estado-pós moderno. Belo Horizonte: Fórum, 2009.

DI PIETRO, Maria Sylvia Zanella. Parcerias na administração pública: concessão, permissão, franquia, terceirização, parceria público-privada e outras formas. 10. ed. São Paulo: Atlas, 2015.

DINIZ, Eli. Governabilidade, governance e reforma do Estado: considerações sobre o novo paradigma. Revista do Serviço Público, Brasília, v. 47, n. 2, p. 5-21, mai-ago 1996.

MOREIRA NETO, Diogo Figueiredo. Curso de direito administrativo. 16.ed. rev. e atual. Rio de Janeiro: Forense, 2014.

OLIVEIRA, Gustavo Henrique Justino de. Parceria público privada e direito ao desenvolvimento: uma abordagem necessária. Revista de Direito da Procuradoria Geral, Rio de Janeiro, n. 60, 2006.

SANTAMARIA PASTOR, Juan Alfonso. Principios de Derecho Administrativo General. .2 ed. Madrid: Lustel, 2009. v.2.

SILVA, Gustavo Tavares da. Políticas públicas e Intersetorialidade: uma discussão sobre a democratização do Estado. Revista Cadernos Metrópole, São Paulo, v. 19, pp. 81-97, 1. sem. 2008.

Como citar: NORA, Luiz Fernando Zen; ARNOLDI, Paulo Roberto Colombo. O Estado e a atuação em parceria com a sociedade civil no 
desenvolvimento de ações de interesse público. Scientia Iuris, Londrina, v. 20, n. 2, p.51-80, jul. 2016. DOI: 10.5433/2178-8189.2016v20n2p51. ISSN: 2178-8189.

Submetido em 10/05/2015

Aprovado em 29/05/2016 